Article

\title{
Study on the Influence of Borehole Heat Capacity on Deep Coaxial Borehole Heat Exchanger
}

\author{
Changlong Wang, Han Fang, Xin Wang, Jinli Lu and Yanhong Sun *
}

check for updates

Citation: Wang, C.; Fang, H.; Wang, X.; Lu, J.; Sun, Y. Study on the Influence of Borehole Heat Capacity on Deep Coaxial Borehole Heat Exchanger. Sustainability 2022, 14, 2043. https://doi.org/10.3390/ su14042043

Academic Editor: Cinzia Buratti

Received: 29 December 2021

Accepted: 9 February 2022

Published: 11 February 2022

Publisher's Note: MDPI stays neutral with regard to jurisdictional claims in published maps and institutional affiliations.

Copyright: (C) 2022 by the authors. Licensee MDPI, Basel, Switzerland. This article is an open access article distributed under the terms and conditions of the Creative Commons Attribution (CC BY) license (https:// creativecommons.org/licenses/by/ $4.0 /)$.
Department of Civil Engineering and Architecture, Anhui University of Technology, Ma'anshan 243002, China; clwang2017@163.com (C.W.); Fhan1007@163.com (H.F.); 15249055726@163.com (X.W.); lujinli@sina.cn (J.L.)

* Correspondence: sunyanhong0623@163.com

\begin{abstract}
Based on a semi-analytical model established previously for heat transfer in coaxial borehole heat exchangers, the influences of the heat capacities of different parts of the borehole (fluid, pipes and grout) on the performance of deep coaxial borehole heat exchanger (DCBHE) are analyzed. The results are as follows: the heat transfer performance of DCBHE will be underestimated if the heat capacities of different parts of the borehole are ignored; the influences of the heat capacities of different parts of the borehole on the performance of DCBHE are more obvious in the early stage, and gradually weaken with the increasing of time; among the heat capacities of different parts of the borehole, the influence of the fluid heat capacity on the performance of DCBHE is the greatest, and the influence of the pipe heat capacities is the least. Under the working condition studied in this paper, the results obtained with considering the heat capacities of different parts of the borehole are compared to ones ignoring heat capacities of selected elements. It was found that ignoring the fluid heat capacity led to a $0.29^{\circ} \mathrm{C}$ lower estimated outlet fluid temperature after $60 \mathrm{~h}$. Omitting the heat capacities of pipes and grout gave $0.03{ }^{\circ} \mathrm{C}$ and $0.13{ }^{\circ} \mathrm{C}$ lower outlet fluid temperatures after $60 \mathrm{~h}$, respectively. The larger the borehole radius, the greater the influence of borehole heat capacity. The geothermal gradient has little effect on the influence of borehole heat capacity on the performance of DCBHE. The results show that the heat capacities of different parts of the borehole have important effects on the performance of DCBHE, especially in the early stage and for a large borehole radius.
\end{abstract}

Keywords: deep coaxial borehole heat exchanger (DCBHE); borehole heat capacity; heat transfer performance; borehole radius; geothermal gradient

\section{Introduction}

As a kind of clean energy, geothermal energy is widely studied, and geothermal energy conversion is often realized through a ground-source heat pump system. Compared with the traditional shallow ground heat exchanger, the deep borehole heat exchanger can obtain more heat from soil; it has therefore been widely studied by researchers around the world [1]. Deep coaxial borehole heat exchanger (DCBHE) has the characteristics of good heat transfer performance and structural stability, and it is a common type of deep borehole heat exchanger for extracting medium-deep geothermal energy [2].

At present, most publications in the literature analyze the influence of pipe diameter, flow velocity and thermal conductivity of heat exchanger materials on the performance of coaxial borehole heat exchanger (CBHE) [3-8]. Zanchini et al. [3] analyzed the influences of thermal short circuit and flow rate on the performance of shallow CBHE under winter and summer conditions by a finite element method, and found that thermal short circuit and flow rate had a very important impact on the performance of shallow CBHE, which can be improved by increasing the internal pipe diameter while keeping the external pipe diameter unchanged. Qi et al. [4] established a 3D numerical heat transfer model of shallow $\mathrm{CBHE}$, and investigated the influences of the combination of different pipe diameters on the outlet temperature and the heat transfer performance of shallow CBHE. 
They found that a larger external pipe diameter was more suitable for practical engineering of shallow CBHE. Wang et al. [5] analyzed the influences of flow direction, flow rate, soil thermal properties, internal and external pipe wall thermal resistances, pipe diameter and other factors on the thermal performance of DCBHE based on a numerical model, and put forward some suggestions for optimizing the thermal performance of DCBHE. Liu et al. [6] established a numerical model of DCBHE based on Fluent software, analyzed the influence of pipe diameters and insulation layer length on the performance of DCBHE, and found that increasing the external pipe diameter and reducing the internal pipe diameter were conducive to improving the outlet fluid temperature and performance of DCBHE. Laying an insulation layer on the internal pipes can effectively enhance the performance; however, the influence of internal pipes insulation layer is not obvious for a large flow rate. Li et al. [7] analyzed the effects of the thermal conductivity of internal pipes and the flow rate on a DCBHE by developing a numerical model based on COMSOL software, and the result showed that larger thermal conductivity of internal pipe would enhance the thermal short circuit between the fluids in the internal and external pipes, and that the outlet fluid temperature would first increase and then decrease with the increase of flow rate. Du et al. [8] established a numerical model of DCBHE under the condition of non-interference heat transfer, and studied the influencing factors of nominal heat extraction of DCBHE. The results showed that the nominal heat extraction of DCBHE increased with increases in borehole depth, ground heat flow, flow rate and the annual average temperature of the local atmosphere. In addition, smaller thermal conductivity of shallow soil layers and the larger thermal conductivity of deep soil layers can improve the nominal heat extraction of DCBHE.

The borehole heat capacity mainly includes the fluid heat capacity, pipe heat capacity and grout heat capacity. It has been found that the borehole heat capacity has a certain impact on the short-time thermal response of CBHE. Therefore, the borehole heat capacity needs to be considered when building the CBHE model [9-13]. Some papers analyze the impact of the borehole heat capacity on the performance of CBHE [14,15]. Nian et al. [14] built a new analytical model based on a thermal response function with consideration of borehole heat capacity, and quantitatively analyzed the effects of borehole heat capacity on ground temperature, fluid temperature and influence radius. It was found that borehole heat capacity had a great influence on the ground temperature, fluid temperature and influence radius in a short time, but the influence weakened with time. Yang et al. [15] developed a transient numerical model that considered the borehole heat capacity by changing the heat flux boundary condition, and quantitatively analyzed the influence of borehole heat capacity and other parameters on the thermal performance of CBHE. The results showed that the influence of borehole heat capacity was greater in a short time and weakened with time. However, both $[14,15]$ analyze the borehole heat capacity as a whole.

Among the above studies, there are few on the influence of the heat capacity of each part of the borehole on the performance of DCBHE, which needs further research. Therefore, based on a semi-analytical model of CBHE considering the geothermal gradient and the heat capacities of different parts of the borehole built by Wang et al. [16], the influences of the heat capacities of different parts of the borehole (fluid, pipes and grout) on the performance of DCBHE are systematically analyzed in this paper. At the same time, the influences of the borehole heat capacity on the performance of DCBHE under different borehole radii and geothermal gradients are analyzed.

\section{Semi-Analytical Model}

Figure 1 shows the cross-section and schematic diagram of a borehole of DCBHE. For the DCBHE, the fluid normally flows into the external pipe and flows out from the internal pipe. Therefore, the semi-analytical model of DCBHE is introduced as follows. 


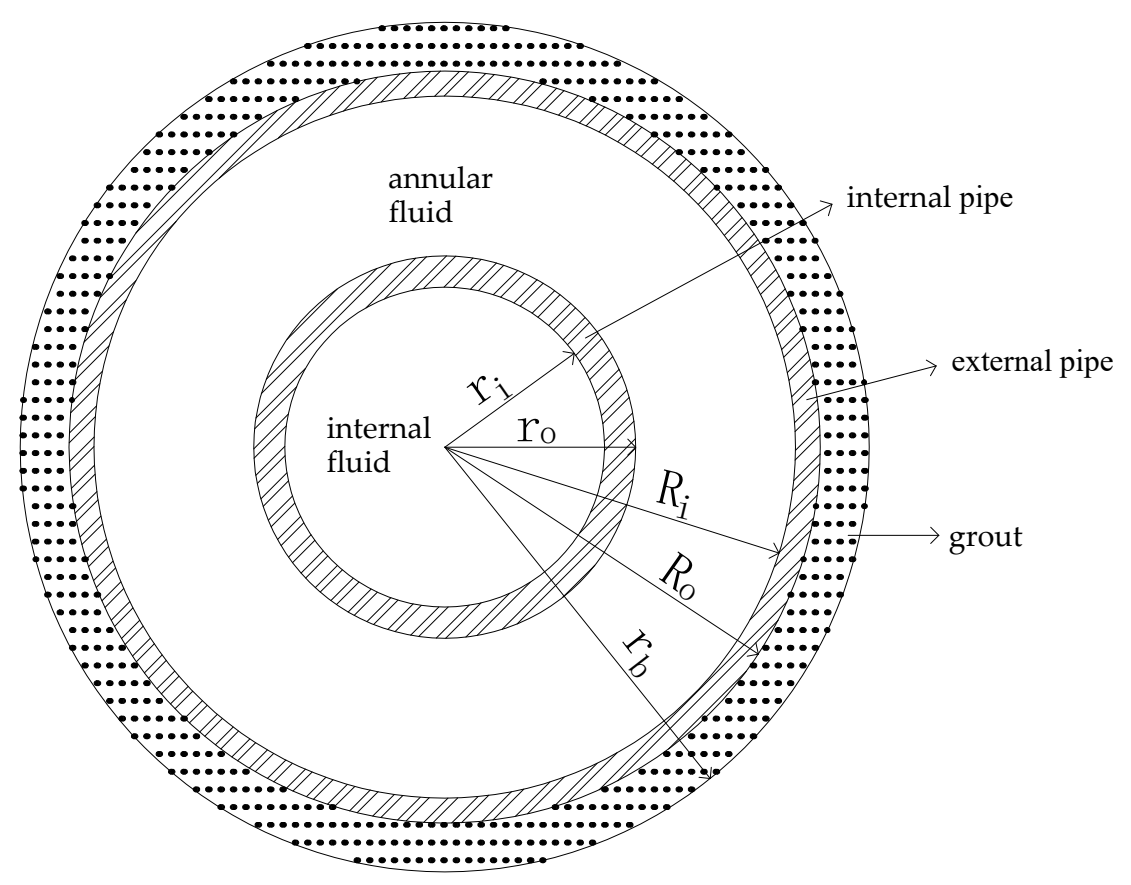

(a)

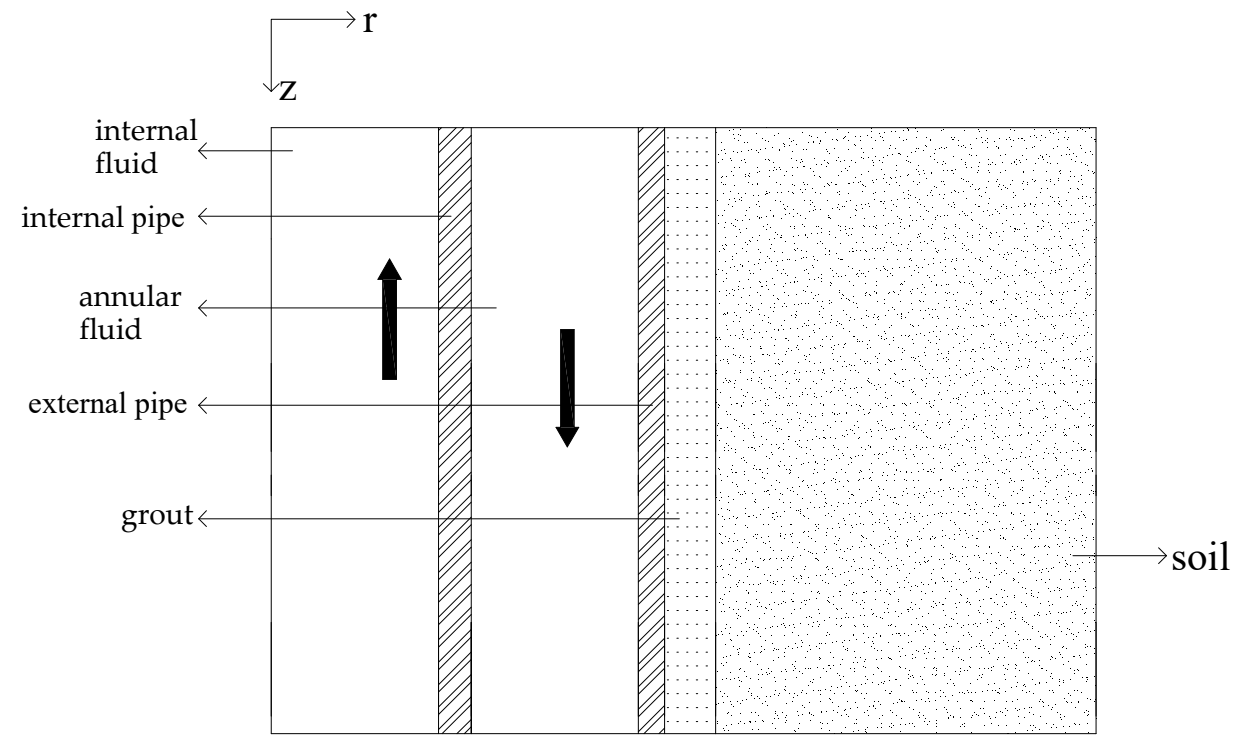

(b)

Figure 1. (a) Cross-section of a borehole of DCBHE; (b) schematic diagram of a DCBHE.

For the internal fluid, the energy equation can be written as follows:

$$
\left[\pi r_{\mathrm{i}}^{2}(\rho c)_{\mathrm{f}}+\pi\left(r_{\mathrm{o}}^{2}-r_{\mathrm{i}}^{2}\right)(\rho c)_{\mathrm{p}}\right] \frac{\partial T_{\mathrm{i}}}{\partial t}=M c_{\mathrm{f}} \frac{\partial T_{\mathrm{i}}}{\partial z}+\frac{T_{\mathrm{a}}-T_{\mathrm{i}}}{R_{\mathrm{ia}}}
$$

where $r_{\mathrm{i}}$ is the inner radius of the internal pipe, $\mathrm{m} ; r_{\mathrm{o}}$ is the outer radius of the internal pipe, $\mathrm{m} ;(\rho c)_{\mathrm{f}}$ is the volumetric heat capacity of the fluid, $\mathrm{J} \cdot \mathrm{m}^{-3} \cdot \mathrm{K}^{-1} ;(\rho c)_{\mathrm{p}}$ is the volumetric heat capacity of the internal/external pipes, $\mathrm{J} \cdot \mathrm{m}^{-3} \cdot \mathrm{K}^{-1} ; c_{\mathrm{f}}$ is the specific heat capacity of the fluid, $\mathrm{J} \cdot \mathrm{kg}^{-1} \cdot \mathrm{K}^{-1} ; M$ is the mass flow rate of the fluid, $\mathrm{kg} \cdot \mathrm{s}^{-1} ; R_{\mathrm{ia}}$ is thermal resistance between the internal fluid and the annular fluid, $\mathrm{m} \cdot \mathrm{K} \cdot \mathrm{W}^{-1} ; T_{\mathrm{i}}$ is the temperature of the internal fluid, ${ }^{\circ} \mathrm{C} ; T_{\mathrm{a}}$ is the temperature of the annular fluid, ${ }^{\circ} \mathrm{C} ; t$ is the time, $\mathrm{s} ; z$ is the depth, $m$. 
The energy equation of the annular fluid can be obtained:

$$
\left[\pi\left(R_{\mathrm{i}}^{2}-r_{\mathrm{o}}^{2}\right)(\rho c)_{\mathrm{f}}+\pi\left(R_{\mathrm{o}}^{2}-R_{\mathrm{i}}^{2}\right)(\rho c)_{\mathrm{p}}\right] \frac{\partial T_{\mathrm{a}}}{\partial t}=-M c_{\mathrm{f}} \frac{\partial T_{\mathrm{a}}}{\partial z}+\frac{T_{\mathrm{i}}-T_{\mathrm{a}}}{R_{\mathrm{ia}}}-q
$$

where $R_{\mathrm{i}}$ is the inner radius of the internal pipe, $\mathrm{m} ; R_{\mathrm{o}}$ is the outer radius of the internal pipe, $\mathrm{m} ; q$ is the heat flow from the annular fluid to the grout, which varies with depth and time.

$$
q=\frac{T_{\mathrm{a}}-T_{\mathrm{eo}}}{R_{\mathrm{ae}}}
$$

where $T_{\mathrm{eo}}$ is the temperature of the external surface of the external pipe, ${ }^{\circ} \mathrm{C} ; R_{\mathrm{ae}}$ is the thermal resistance between the annular fluid and external surface of the external pipe, $\mathrm{m} \cdot \mathrm{K} \cdot \mathrm{W}^{-1}$.

For the grout and soil, 1D radial heat transfer can be assumed, and the energy equation is as follows:

$$
\begin{gathered}
T_{\mathrm{eo}}=T_{0}+\frac{q}{k_{\mathrm{g}}} G(t) \\
G(t)=\frac{8 k_{0}}{\pi^{5} \delta^{2}} \int_{0}^{\infty} \frac{1-\exp \left[-\frac{k_{\mathrm{g}} t}{(\rho c)_{\mathrm{g}} R_{0}^{2}} \beta^{2}\right]}{\beta^{5}\left(\phi^{2}+\psi^{2}\right)} \mathrm{d} \beta
\end{gathered}
$$

where $T_{0}$ is the initial temperature of the soil, ${ }^{\circ} \mathrm{C} ; k_{\mathrm{g}}$ is the thermal conductivity of the grout, $\mathrm{W} \cdot \mathrm{m}^{-1} \cdot \mathrm{K}^{-1} ; \mathrm{G}(t)$ is the G-function; $(\rho c)_{\mathrm{g}}$ is the volumetric heat capacity of the grout, $\mathrm{J} \cdot \mathrm{m}^{-3} \cdot \mathrm{K}^{-1} ; \beta$ is the integration variable; $k_{0}, \delta, \phi$ and $\psi$ are the intermediate variables.

The boundary conditions are as follows:

$$
\begin{gathered}
T_{\mathrm{a}}=T_{\mathrm{i}}+\frac{Q}{M c_{\mathrm{f}}},(z=0, t>0) \\
T_{\mathrm{i}}=T_{\mathrm{a}},(z=L, t>0)
\end{gathered}
$$

where $Q$ is the heat input rate, $\mathrm{W} ; L$ is the DCBHE length, $\mathrm{m}$.

Initial condition is as follows:

$$
T_{\mathrm{i}}=T_{\mathrm{a}}=T_{0}=T_{\text {sur }}+a z,(t=0)
$$

where $T_{\text {sur }}$ is the temperature of the soil surface, ${ }^{\circ} \mathrm{C} ; a$ is the geothermal gradient, ${ }^{\circ} \mathrm{C} \cdot \mathrm{m}^{-1}$. More details of the semi-analytical model can be seen in [16].

\section{Study on the Influences of Heat Capacities of Different Parts of Borehole}

In order to more accurately analyze the influence of heat capacities of different parts of borehole (fluid, pipes and grout) on the performance of DCBHE, the semi-analytical model in [16] was applied to a typical DCBHE with a depth of $2000 \mathrm{~m}$. Other relevant parameters are shown in Table 1.

Table 1. Geometric parameters and thermal properties of the typical DCBHE [17].

\begin{tabular}{ccc}
\hline Parameter & Symbol & Value \\
DCBHE length & $L$ & $2000 \mathrm{~m}$ \\
Borehole radius & $r_{\mathrm{b}}$ & $0.1 \mathrm{~m}$ \\
Inner radius of the internal pipe & $r_{\mathrm{i}}$ & $0.03766 \mathrm{~m}$ \\
Outer radius of the internal pipe & $r_{\mathrm{o}}$ & $0.045 \mathrm{~m}$ \\
Inner radius of the external pipe & $R_{\mathrm{i}}$ & $0.08263 \mathrm{~m}$ \\
Outer radius of the external pipe & $R_{\mathrm{o}}$ & $0.0885 \mathrm{~m}$ \\
Thermal conductivity of the internal/external pipes & $\lambda_{\mathrm{p}}$ & $0.5 \mathrm{~W} \cdot \mathrm{m}^{-1} \cdot \mathrm{K}^{-1}$ \\
\hline
\end{tabular}


Table 1. Cont.

\begin{tabular}{ccc}
\hline Parameter & Symbol & Value \\
\hline Volumetric heat capacity of the internal/external pipes & $(\rho c)_{\mathrm{p}}$ & $1.85 \times 10^{6} \mathrm{~J} \cdot \mathrm{m}^{-3} \cdot \mathrm{K}^{-1}$ \\
Thermal conductivity of the grout & $\lambda_{\mathrm{g}}$ & $0.73 \mathrm{~W} \cdot \mathrm{m}^{-1} \cdot \mathrm{K}^{-1}$ \\
Volumetric heat capacity of the grout & $(\rho c)_{\mathrm{g}}$ & $3.8 \times 10^{6} \mathrm{~J} \cdot \mathrm{m}^{-3} \cdot \mathrm{K}^{-1}$ \\
Thermal conductivity of the soil & $\lambda_{\mathrm{s}}$ & $3.25 \mathrm{~W} \cdot \mathrm{m}^{-1} \cdot \mathrm{K}^{-1}$ \\
Volumetric heat capacity of the soil & $(\rho c)_{\mathrm{s}}$ & $2.24 \times 10^{6} \mathrm{~J} \cdot \mathrm{m}^{-3} \cdot \mathrm{K}^{-1}$ \\
Thermal conductivity of the fluid & $\lambda_{\mathrm{f}}$ & $0.59 \mathrm{~W} \cdot \mathrm{m}^{-1} \cdot \mathrm{K}^{-1}$ \\
Volumetric heat capacity of the fluid & $(\rho c)_{\mathrm{f}}$ & $4.19 \times 10^{6} \mathrm{~J} \cdot \mathrm{m}^{-3} \cdot \mathrm{K}^{-1}$ \\
Mass flow rate of the fluid & $M$ & $11.6 \mathrm{~kg} \cdot \mathrm{s}^{-1}$ \\
Temperature of the soil surface & $T_{\mathrm{sur}}$ & $15^{\circ} \mathrm{C}$ \\
Geothermal gradient & $a$ & $0.03^{\circ} \mathrm{C} \cdot \mathrm{m}^{-1}$ \\
Heat input rate & $Q$ & $-200,000 \mathrm{~W}$ \\
\hline
\end{tabular}

\subsection{Study on the Influences of the Fluid Heat Capacity and Borehole Heat Capacity}

Figure 2 shows the comparison diagram of fluid temperature distributions for only ignoring the fluid heat capacity, ignoring the borehole heat capacity and considering the heat capacities of different parts of the borehole at different times. At $2 \mathrm{~h}, 10 \mathrm{~h}, 40 \mathrm{~h}$ and $60 \mathrm{~h}$, compared with the fluid temperatures for considering the heat capacities of different parts of the borehole, the minimum deviations of the fluid temperatures for only ignoring the fluid heat capacity are $3.30{ }^{\circ} \mathrm{C}, 1.29^{\circ} \mathrm{C}, 0.41{ }^{\circ} \mathrm{C}$ and $0.29^{\circ} \mathrm{C}$, respectively, and the minimum deviations of the fluid temperatures for ignoring the borehole heat capacity are $4.24^{\circ} \mathrm{C}, 1.69^{\circ} \mathrm{C}, 0.60^{\circ} \mathrm{C}$ and $0.45^{\circ} \mathrm{C}$, respectively. It can be seen that the influence trends of only ignoring the fluid heat capacity and ignoring the borehole heat capacity on the heat exchanger are the same. The influence of the fluid heat capacity on the fluid temperature distribution is obvious in the early stage and gradually weakens in the later stage. However, ignoring the borehole heat capacity has a more obvious effect on the fluid temperature distribution. In addition, it can be seen from Figure 2 that for the shallow soil layer, the annular fluid temperature is a little lower than the inlet fluid temperature at an early time, which can be explained as follows: the soil temperature in the shallow layer is lower than the annular fluid temperature, and after the annular fluid enters into the external pipe, heat would be transferred from the annular fluid to the soil; but the fluid temperature gradually decreases with time, and the temperature difference between the annular fluid and the shallow-layer soil gradually decreases, so that this phenomenon would disappear after some time.

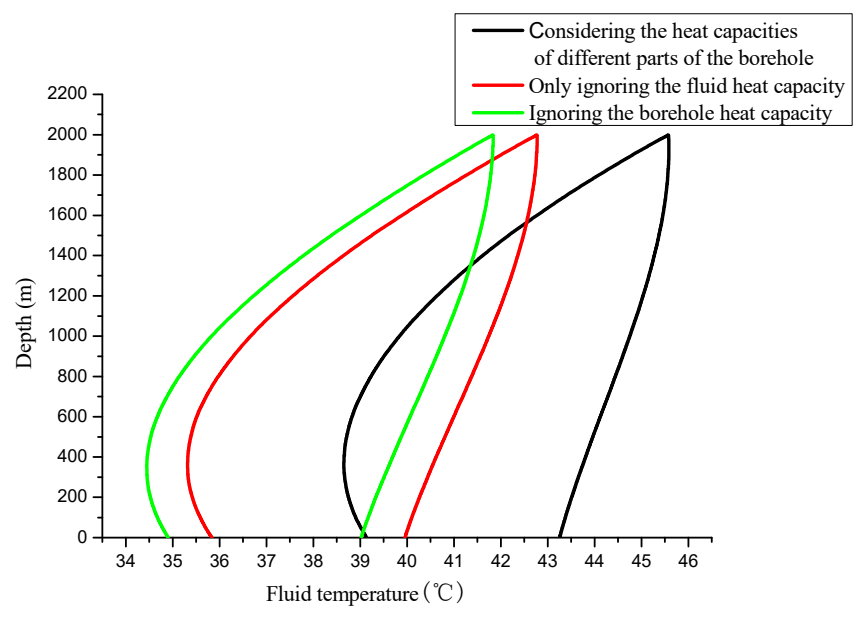

(a)

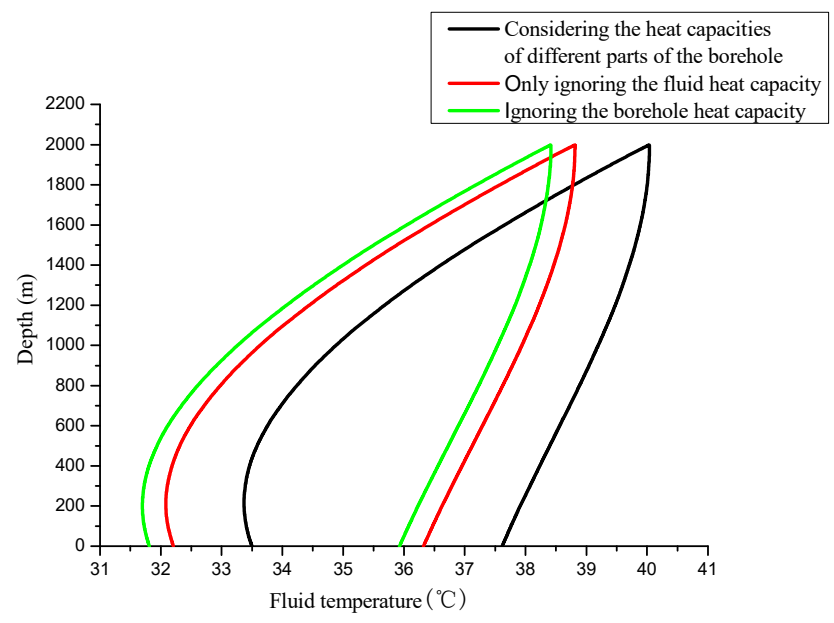

(b)

Figure 2. Cont. 


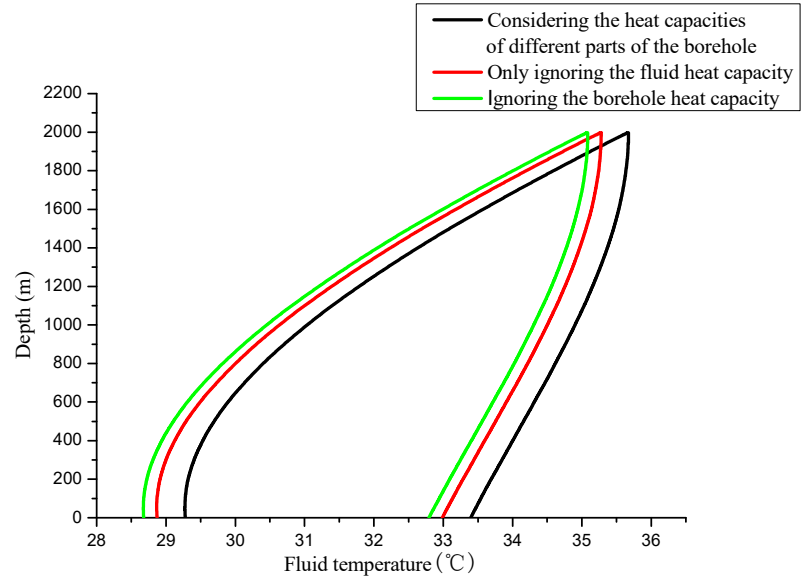

(c)

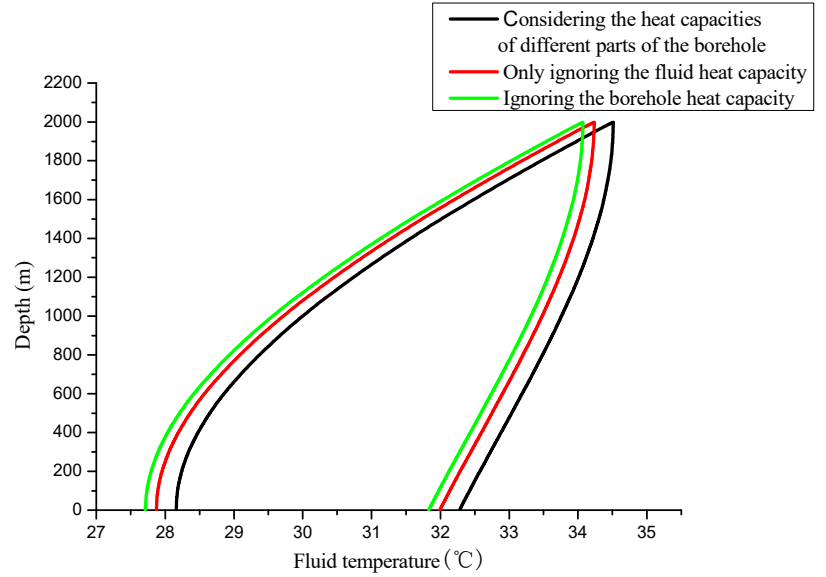

(d)

Figure 2. Comparison diagram of fluid temperature distributions for only ignoring the fluid heat capacity, ignoring the borehole heat capacity and considering the heat capacities of different parts of the borehole at different times: (a) $2 \mathrm{~h}$, (b) $10 \mathrm{~h}$, (c) $40 \mathrm{~h}$, (d) $60 \mathrm{~h}$.

Figure 3 shows the comparison diagram of the outlet fluid temperatures for only ignoring the fluid heat capacity, ignoring the borehole heat capacity and considering the heat capacities of different parts of the borehole. It can be seen that the influence of only ignoring the fluid heat capacity and ignoring the borehole heat capacity on the outlet temperature decreases with the increase in time. At $10 \mathrm{~h}$ and $20 \mathrm{~h}$, compared with the fluid temperatures for considering the heat capacities of different parts of the borehole, the deviations of the outlet fluid temperatures for only ignoring the fluid heat capacity were $1.29^{\circ} \mathrm{C}$ and $0.73^{\circ} \mathrm{C}$, respectively, and the deviations of the outlet fluid temperatures for ignoring the borehole heat capacity were $1.69{ }^{\circ} \mathrm{C}$ and $1.01^{\circ} \mathrm{C}$, respectively. It can be found that in the early stage, the heat capacity had a great impact on the outlet fluid temperature. The reason is as follows: when only the fluid heat capacity or the borehole heat capacity is ignored, the fluid temperature decreases quickly in the early stage, but there is no heat stored in the fluid, and the difference between the fluid temperature and the soil temperature is relatively large, so that the fluid temperature is low. However, with the increase in time, the influence of only ignoring the fluid heat capacity and ignoring the borehole heat capacity on the fluid temperature begins to weaken. After $110 \mathrm{~h}$, the deviation among only ignoring the fluid heat capacity, ignoring the borehole heat capacity and considering the heat capacities of different parts of the borehole was less than $0.3^{\circ} \mathrm{C}$, which was because with the increase in time; the fluid temperatures thus varied slowly and the heat exchange tended to be stable. The influence of fluid heat capacity and borehole heat capacity on the heat transfer performance of DCBHE also gradually weakened and tended to be stable.

\subsection{Study on the Influences of the Pipe Heat Capacities and Grout Heat Capacity}

Figure 4 shows the comparison diagram of fluid temperature distributions for only ignoring the heat capacities of pipes, only ignoring the heat capacity of grout and considering the heat capacities of different parts of the borehole at different times. At $2 \mathrm{~h}, 10 \mathrm{~h}, 40 \mathrm{~h}$ and $60 \mathrm{~h}$, compared with the fluid temperatures for considering the heat capacities of different parts of the borehole, the minimum deviations of the fluid temperatures for only ignoring the pipe heat capacities were $0.09{ }^{\circ} \mathrm{C}, 0.14{ }^{\circ} \mathrm{C}, 0.05^{\circ} \mathrm{C}$ and $0.03{ }^{\circ} \mathrm{C}$, respectively, and the minimum deviations of the fluid temperatures for only ignoring the grout heat capacity were $0.16^{\circ} \mathrm{C}, 0.28^{\circ} \mathrm{C}, 0.15^{\circ} \mathrm{C}$ and $0.13{ }^{\circ} \mathrm{C}$, respectively. It can be seen that the influence trends of only ignoring the pipe heat capacities and only ignoring the grout heat capacity on the DCBHE are consistent. In the early stage, only ignoring the grout heat capacity had a large impact on the fluid temperature, and only ignoring the pipe heat capacities had 
a small impact on the fluid temperature. Compared with Figure 2, it can be found that the influence trends for ignoring the heat capacities of different parts of the borehole on the performance of DCBHE were basically the same, in which only ignoring the fluid heat capacity had the greatest influence on the performance of DCBHE, and only ignoring the pipe heat capacities had the least influence on the performance of DCBHE.

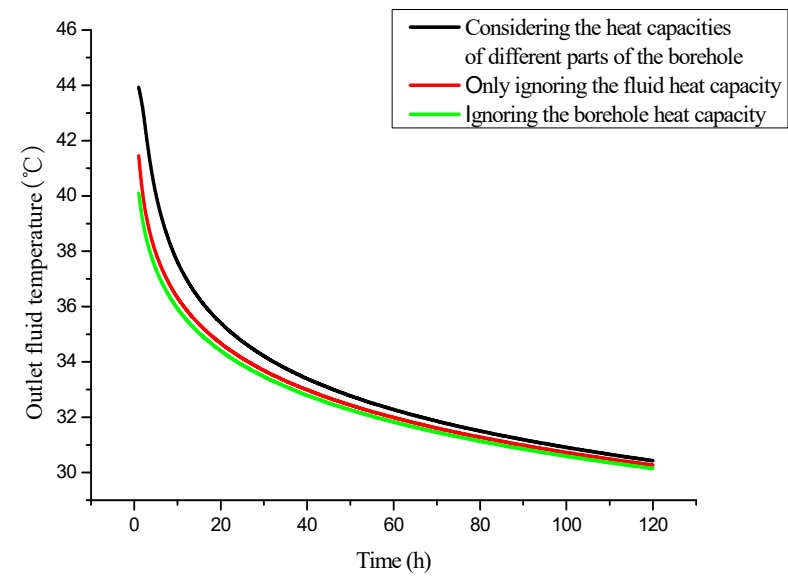

Figure 3. Comparison diagram of outlet fluid temperatures for only ignoring the fluid heat capacity, ignoring the borehole heat capacity and considering the heat capacities of different parts of the borehole.

Figure 5 shows the comparison diagram of outlet fluid temperatures for only ignoring the pipe heat capacities, only ignoring the grout heat capacity and considering the heat capacities of different parts of the borehole. With the increase in time, the influences of only ignoring the pipe heat capacities and only ignoring the grout heat capacity on the outlet fluid temperature weakened. At $25 \mathrm{~h}$, the deviation among the outlet fluid temperatures for only ignoring the pipe heat capacities, only ignoring the grout heat capacity and considering the heat capacities of different parts of the borehole was about $0.2^{\circ} \mathrm{C}$. At $110 \mathrm{~h}$, the deviation among them was about $0.1^{\circ} \mathrm{C}$. In addition, it can be seen from Figure 5 that only ignoring the pipe heat capacities and only ignoring the grout heat capacity had little impact on the outlet fluid temperature, which was because the pipe heat capacities and grout heat capacity were relatively small, and their impacts on the performance of DCBHE were relatively small. In addition, it can be seen from Figures 3 and 5 that after considering the heat capacities of different parts of the borehole, the outlet fluid temperature was higher, so that ignoring the borehole heat capacity will lead to underestimation of the heat transfer performance of the heat exchanger.

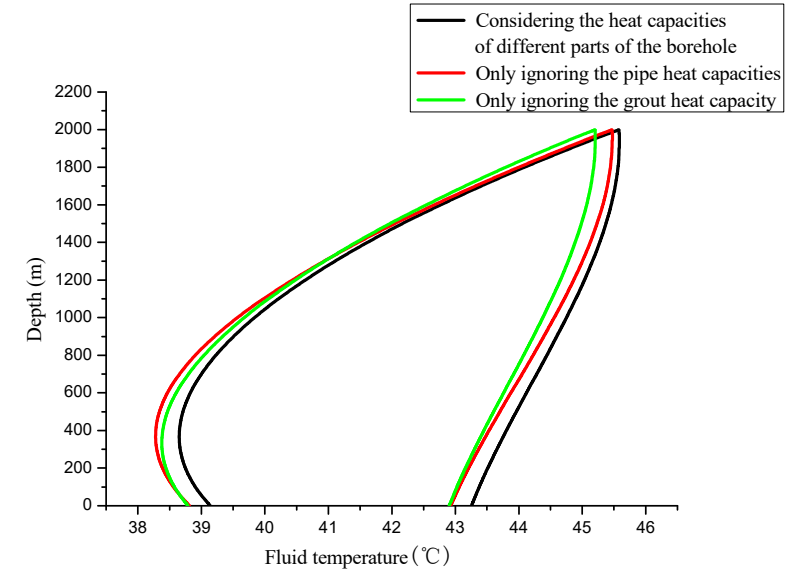

(a)

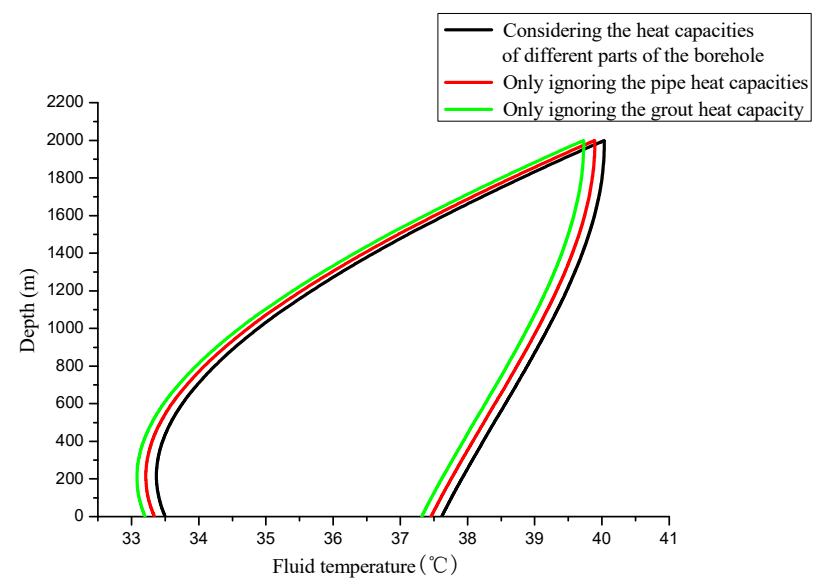

(b)

Figure 4. Cont. 


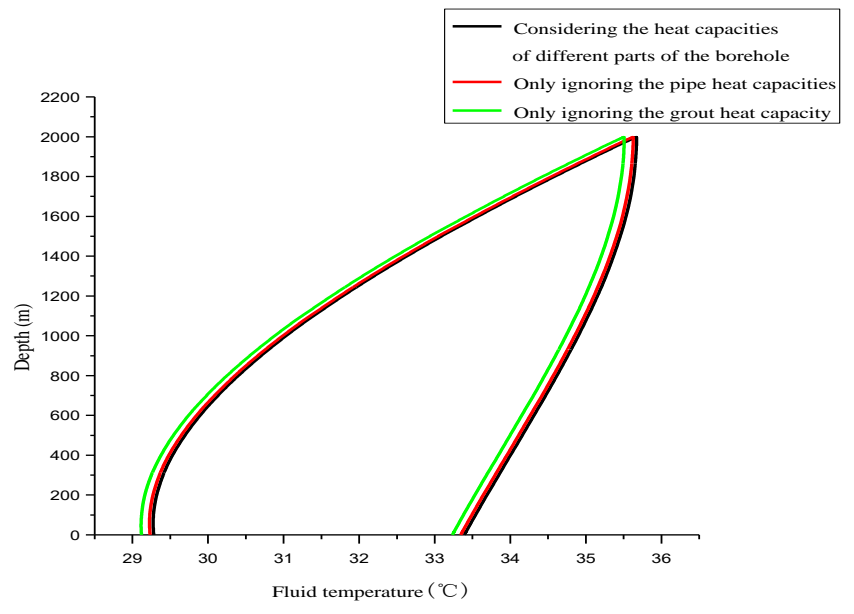

(c)

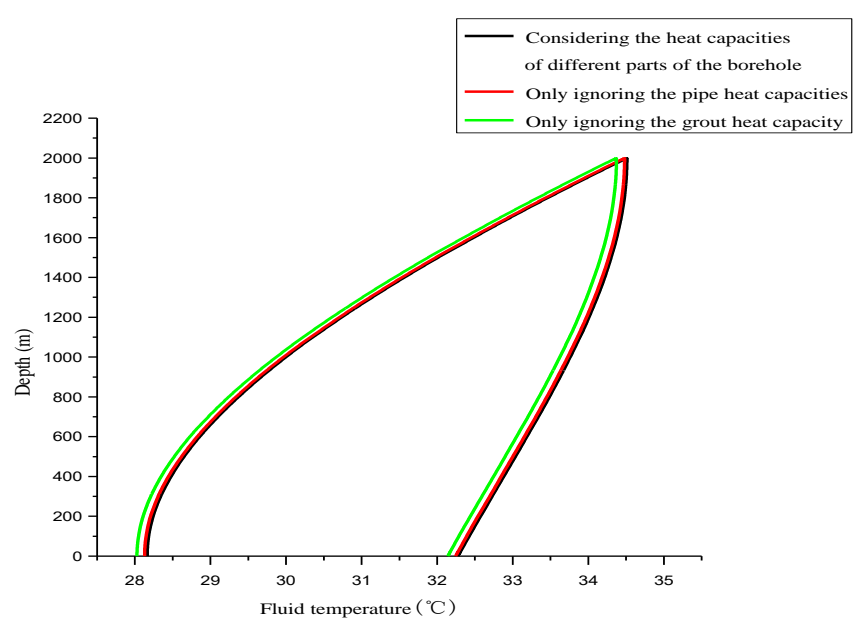

(d)

Figure 4. Comparison diagram of fluid temperature distributions for only ignoring the pipe heat capacities, only ignoring the grout heat capacity and considering the heat capacities of different parts of the borehole at different times: (a) $2 \mathrm{~h}$, (b) $10 \mathrm{~h}$, (c) $40 \mathrm{~h}$, (d) $60 \mathrm{~h}$.

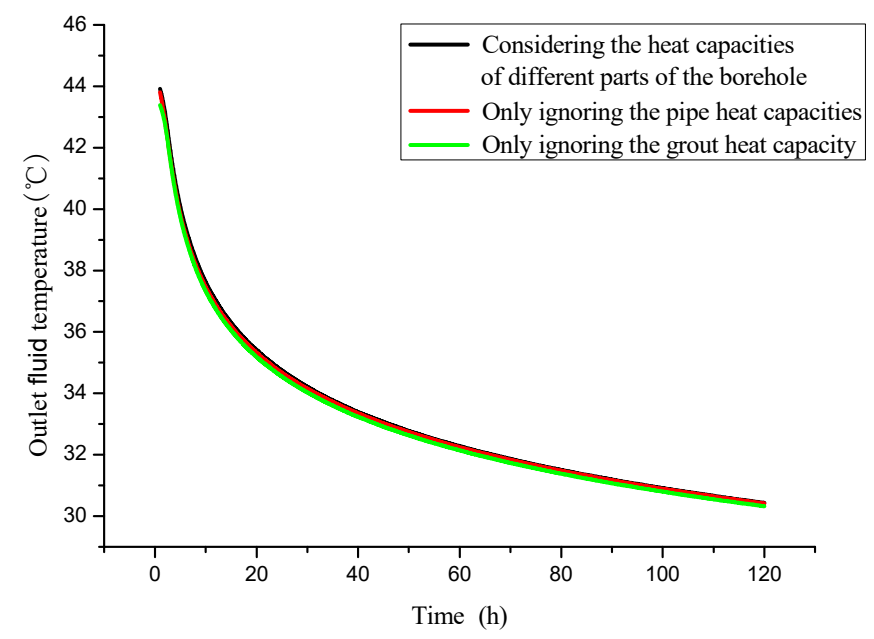

Figure 5. Comparison of outlet fluid temperatures for only ignoring the pipe heat capacities, only ignoring the grout heat capacity and considering the heat capacities of different parts of the borehole.

\section{Study on the Influences of Borehole Heat Capacity under Different Borehole Radii}

In order to study the influence of the heat capacities of different parts of the borehole under different borehole radii on the performance of DCBHE, the influences of the borehole heat capacity under two borehole radii are compared, one is the borehole radius $r_{\mathrm{b}}=0.1 \mathrm{~m}$ as shown in Table 1, and the other borehole parameters are as follows: borehole radius $r_{\mathrm{b}}=0.06 \mathrm{~m}$, the inner radius of the internal pipe $r_{\mathrm{i}}=0.018 \mathrm{~m}$, the inner radius of the external pipe $R_{\mathrm{i}}=0.043 \mathrm{~m}$, the outer radius of the internal pipe $r_{\mathrm{o}}=0.025 \mathrm{~m}$, and the outer radius of the external pipe $R_{\mathrm{o}}=0.048 \mathrm{~m}$. Figure 6 shows the influences of borehole heat capacity on outlet fluid temperature under different borehole radii. For the borehole radius $r_{\mathrm{b}}=0.1 \mathrm{~m}$, at $120 \mathrm{~h}$, the deviation between the outlet fluid temperatures for ignoring the borehole heat capacity and considering the heat capacities of different parts of the borehole was still $0.28{ }^{\circ} \mathrm{C}$. For the borehole radius $r_{\mathrm{b}}=0.06 \mathrm{~m}$, at $120 \mathrm{~h}$, the deviation between the outlet fluid temperatures for ignoring the borehole heat capacity and considering the heat capacities of different parts of the borehole was only $0.16^{\circ} \mathrm{C}$. It can be seen that the smaller the borehole radius, the smaller the impact of the borehole heat capacity on the outlet fluid temperature. For larger borehole radius, the borehole heat capacity is larger, and the impact of the borehole heat capacity on the performance of DCBHE is larger. Therefore, the larger 
the borehole radius, the greater the impact of the borehole heat capacity on the performance of DCBHE, and it is necessary to consider the borehole heat capacity when building the heat transfer model of DCBHE.

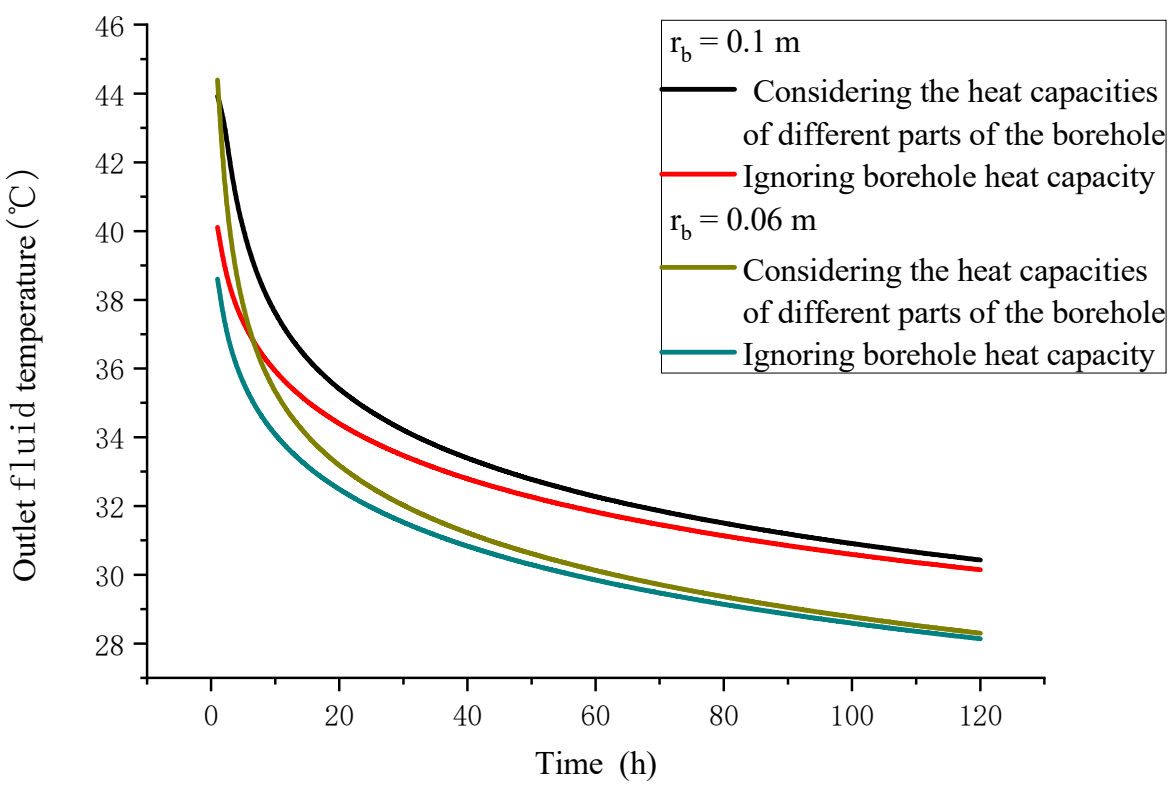

Figure 6. Comparison diagram of outlet fluid temperatures for ignoring borehole heat capacity and considering the heat capacities of different parts of the borehole under different borehole radii.

\section{Study on the Influences of Borehole Heat Capacity under Different Geothermal Gradients}

In order to study the influences of borehole heat capacity on the performance of DCBHE under different geothermal gradients, the influences of borehole heat capacity under three different geothermal gradients are analyzed in this paper. The three different geothermal gradients are $a=0.02{ }^{\circ} \mathrm{C} \cdot \mathrm{m}^{-1}, a=0.03{ }^{\circ} \mathrm{C} \cdot \mathrm{m}^{-1}$ and $a=0.04{ }^{\circ} \mathrm{C} \cdot \mathrm{m}^{-1}$, respectively, and other borehole parameters are shown in Table 1. Figure 7 shows the influences of borehole heat capacity on the outlet fluid temperature under different geothermal gradients. It can be found that the influence trends of borehole heat capacity on the outlet fluid temperature under different geothermal gradients are the same, and that the influence is greatest in the early stage and gradually weakens in the later stage. For the geothermal gradient $a=0.02{ }^{\circ} \mathrm{C} \cdot \mathrm{m}^{-1}$, the deviation between the outlet fluid temperatures for ignoring the borehole heat capacity and considering the heat capacities of different parts of the borehole was still greater than $2.706{ }^{\circ} \mathrm{C}$ during the first $5 \mathrm{~h}$, and the deviation between them was only $0.280{ }^{\circ} \mathrm{C}$ at $120 \mathrm{~h}$. For the geothermal gradient $a=0.03{ }^{\circ} \mathrm{C} \cdot \mathrm{m}^{-1}$, the deviation between the outlet fluid temperatures for ignoring the heat capacity of the borehole and the outlet fluid temperature considering the heat capacity of different parts of the borehole was greater than $2.701{ }^{\circ} \mathrm{C}$ during the first $5 \mathrm{~h}$, and the deviation between them was only $0.281{ }^{\circ} \mathrm{C}$ at $120 \mathrm{~h}$. For the geothermal gradient $a=0.04{ }^{\circ} \mathrm{C} \cdot \mathrm{m}^{-1}$, the deviation between the outlet fluid temperatures for ignoring the borehole heat capacity and considering the heat capacities of different parts of the borehole was greater than $2.696{ }^{\circ} \mathrm{C}$ during the first $5 \mathrm{~h}$, and the deviation between them was only $0.282{ }^{\circ} \mathrm{C}$ at $120 \mathrm{~h}$. Therefore, the influences of borehole heat capacity on the outlet fluid temperature of DCBHE under different geothermal gradients were basically the same. 


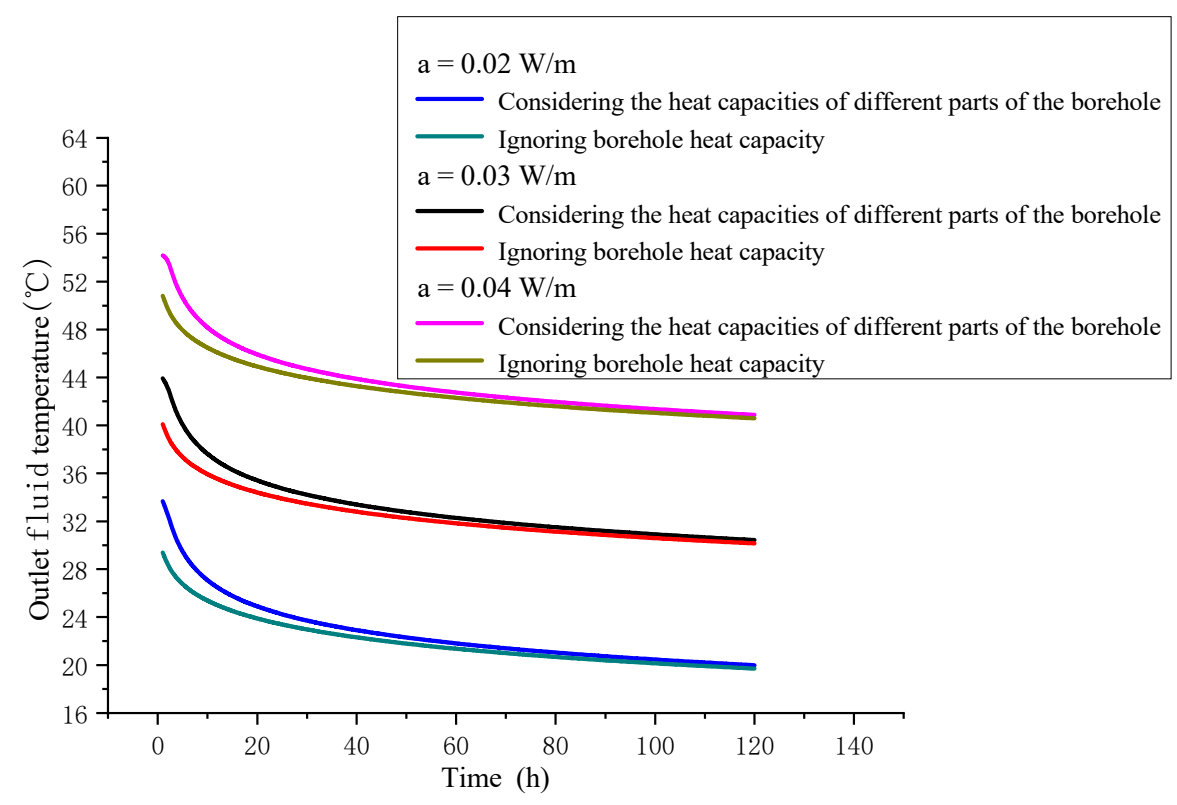

Figure 7. Comparison diagram of outlet fluid temperatures for ignoring borehole heat capacity and considering the heat capacities of different parts of the borehole under different geothermal gradients.

\section{Conclusions}

Based on the heat transfer model of DCBHE, this paper analyzed the influence of the heat capacities of different parts of the borehole (fluid, pipes and grout) on the performance of DCBHE under different borehole radii and geothermal gradients. Some important conclusions are as follows:

(1) The influence trends of the heat capacities of different parts of the borehole on the performance of DCBHE were basically the same, decreasing with the increase in time. In the early stage, ignoring the borehole heat capacity caused a deviation of about $4.24{ }^{\circ} \mathrm{C}$ to the fluid temperature. With the increase in time, the influence of ignoring the borehole heat capacity on the performance of DCBHE gradually weakened.

(2) Among the heat capacities of different parts of the borehole, the impact of the fluid heat capacity on the performance of DCBHE was much greater than those of the heat capacities of the other parts, and the pipe heat capacities had the least impact on the performance of DCBHE. Under the working condition studied in this paper, the results obtained with considering the heat capacities of different parts of the borehole were compared to those ignoring heat capacities of the selected elements. It was found that ignoring the fluid heat capacity led to a $0.29{ }^{\circ} \mathrm{C}$ lower estimated outlet fluid temperature after $60 \mathrm{~h}$. Omitting the heat capacities of pipes gave $0.03{ }^{\circ} \mathrm{C}$, and not taking into account the heat capacity of grout gave a $0.13^{\circ} \mathrm{C}$ lower outlet fluid temperature after $60 \mathrm{~h}$, respectively.

(3) When the borehole radius was larger, the borehole heat capacity had a greater impact on the performance of DCBHE. Under the working condition studied in this paper, ignoring the borehole heat capacity led to a $0.28{ }^{\circ} \mathrm{C}$ lower estimated outlet fluid temperature after $120 \mathrm{~h}$ for $r_{\mathrm{b}}=0.1 \mathrm{~m}$, and to a $0.16^{\circ} \mathrm{C}$ lower estimated outlet fluid temperature after $120 \mathrm{~h}$ for $r_{\mathrm{b}}=0.06 \mathrm{~m}$.

(4) For different geothermal gradients, the influences of borehole heat capacity on the performance of DCBHE were basically the same.

(5) To sum up, the heat capacities of different parts of the borehole have an important impact on the performance of DCBHE, especially in the early stage and when the borehole radius is large. 


\begin{abstract}
Author Contributions: Conceptualization, Abstract, Sections 1 and 5 were contributed jointly by C.W. and Y.S. Section 2 was authored by C.W. and H.F. Section 3 was written by X.W. and J.L. Section 4 was authored by H.F. and X.W. Paper writing coordination was carried out by Y.S. and editing by H.F. All authors have read and agreed to the published version of the manuscript.

Funding: It is acknowledged that this project received funding from the Natural Science Foundation of Anhui Province (grant number 2008085QE256) to carry out the research reported in this paper.
\end{abstract}

Institutional Review Board Statement: Not applicable.

Informed Consent Statement: Not applicable.

Data Availability Statement: Not applicable.

Conflicts of Interest: The authors declare no conflict of interest.

\title{
References
}

1. Zhao, Y.Z.; Ma, Z.B.; Pang, Z.H. A fast simulation approach to the thermal recovery characteristics of deep borehole heat exchanger after heat extraction. Sustainability 2020, 12, 2021. [CrossRef]

2. Guan, C.M.; Zhao, S.W.; Zhang, W.K.; Sun, B.Y. Heat transfer analysis of ground heat exchangers for medium-deep geothermal energy heating. Heat. Vent. Air Cond. 2021, 51, 107-112.

3. Zanchini, E.; Lazzari, S.; Priarone, A. Improving the thermal performance of coaxial borehole heat exchangers. Energy 2010, 35, 657-666. [CrossRef]

4. Qi, Z.S.; Jiang, Y. Analysis of heat transfer characteristics for coaxial tubes underground heat exchanger. J. Jilin Inst. Archit. Civ. Eng. 2012, 29, 51-54.

5. Wang, D.J.; Fang, L.; Hu, S.T.; Shao, Z.K.; Gao, Z.Y.; Diao, N.R. Parameter analysis of the performance of the deep borehole heat exchanger. Dist. Heat. 2018, 3, 1-7.

6. Liu, J.; Cai, W.L.; Wang, F.H.; Wang, Z.H.; Han, E.S. Experimental study and tube structure optimization of deep borehole ground source heat pump. J. Eng. Thermophys. 2019, 40, 2143-2150.

7. Li, Y.Q.; Xu, S.H.; Zhang, W.D.; Sun, Y.L.; Han, Y.L.; Zhang, H.; Huang, J.F. Thermal short-circuiting and heat transfer performance of coaxial borehole heat exchanger. Coal Geol. Explor. 2020, 48, 183-188.

8. Du, T.T.; Man, Y.; Jiang, G.X.; Fang, L.; Fang, Z.H. Transfer modeling and heat extraction analysis of coaxial tubes deep borehole heat exchanger. Renew. Energy Resour. 2020, 38, 887-892.

9. Bandyopadhyay, G.; Gosnold, W.; Mann, M. Analytical and semi-analytical solutions for short-time transient response of ground heat exchangers. Energy Build. 2008, 40, 1816-1824. [CrossRef]

10. Lamarche, L.; Beauchamp, B. New solutions for the short-time analysis of geothermal vertical boreholes. Int. Heat Mass Transf. 2007, 50, 177-184. [CrossRef]

11. Beier, R.A.; Spitler, J.D. Weighted average of inlet and outlet temperatures in borehole heat exchangers. Appl. Energy 2016, 174, 118-129. [CrossRef]

12. Nguyen, A.; Pasquier, P.; Marcotte, D. Thermal resistance and capacity model for standing column wells operating under a bleed control. Renew. Energy 2015, 76, 743-746. [CrossRef]

13. Li, M.; Lai, A.C.K. Analytical model for short-time responses of ground heat exchangers with U-shaped tubes: Model development and validation. Appl. Energy 2013, 104, 510-516. [CrossRef]

14. Nian, Y.L.; Cheng, W.L. Analytical g-function for vertical geothermal boreholes with effect of borehole heat capacity. Appl. Therm. Eng. 2018, 140, 733-744. [CrossRef]

15. Yang, X.Y.; Wang, G.D.; Wang, Q.S.; Chen, C.Q. Transient numerical model for a coaxial borehole heat exchanger with the effect of borehole heat capacity. Int. J. Energy Res. 2019, 43, 6551-6560. [CrossRef]

16. Wang, C.L.; Lu, Y.H.; Chen, L.W.; Huang, Z.J.; Fang, H. A semi-analytical model for heat transfer in coaxial borehole heat exchangers. Geothermics 2021, 89, 101952. [CrossRef]

17. Kong, Y.L.; Chen, C.F.; Shao, H.B.; Pang, Z.H.; Xiong, L.P.; Wang, J.Y. Principle and capacity quantification of deep-borehole heat exchangers. Chin. J. Geophys. 2017, 60, 4741-4752. 